\title{
LOS TERRATENIENTES DE CAUTÍN: ACTORES CLAVES DE LA CONTRARREFORMA
}

\author{
Daniel Barnaby Carter
}




\section{DANIEL BARNABY CARTER}

Daniel Barnaby Carter es Doctor en Historia Latinoamericana por la Universidad de Cambridge. Este trabajo forma parte del proyecto Conicyt No.3150572 Modernity and Authoritarianism. Chilean Landowners from Agrarian Reform to Counter-Reform, 1962-1978, patrocinado por el Departamento de Ciencias Históricas de la Universidad de Chile. 


\section{LOS TERRATENIENTES DE CAUTÍN: ACTORES CLAVES DE LA CONTRARREFORMA}

Enfrentada a un programa de Reforma Agraria cada vez más radicalizado e incapaz de defender sus intereses a través del sistema político imperante, en los años sesenta y comienzos de los setenta la élite terrateniente se vio obligada a buscar otros medios mediante los cuales recuperar su hegemonía. Este artículo trata acerca del rol de un actor clave involucrado en esta lucha: los terratenientes del antiguo territorio de la frontera al sur del valle central y, en particular, la provincia de Cautín. A diferencia de los propietarios más tradicionales del valle central, cuya tenencia se remonta a la época colonial, los colonos de la frontera estaban defendiendo los frutos pioneros obtenidos por sus padres y abuelos de aquello que ellos veían como un retroceso a la anarquía y la barbarie. El artículo busca el origen del modo en que, enfrentados a la posibilidad de perder las frágiles bases de su poder, estos colonos desarrollaron una clara identidad colectiva, una ideología, y una estrategia para debilitar la amenaza de modernización social en el campo. Mi argumento es que esta situación llevó a un fuerte sentido de colectivo o de identidad de clase, un discurso más nacionalistaconservador y una disposición cada vez mayor a hacer uso de la violencia. Aunque la conquista militar (la llamada "pacificación”), el establecimiento de colonizadores y la cuestión indígena definen las provincias llamadas de frontera como algo excepcional, la evidencia recogida en esta zona ayuda a clarificar la reacción de la derecha autoritaria frente a los proyectos de modernización llevados a cabo en Chile durante los periodos presidenciales de Frei y Allende, y a las razones de su derrota definitiva. El conflicto entre los terratenientes y los promotores de la Reforma Agraria en Cautín fue uno de los más importantes semilleros de la mentalidad golpista que habría conducido hacia el golpe militar de septiembre de 1973. Por lo tanto, un análisis de este fenómeno puede entregar importantes antecedentes sobre las razones de este trágico evento.

Entre los terratenientes chilenos había una sensación de que las viejas reglas del juego, gracias a las cuales ellos habían gozado de privilegios y respeto, estaban amenazadas por fuerzas ideológicas más allá de su control, y que ya no permanecerían indemnes al progreso social modernizador que se venía desarrollando en el resto del país desde la erupción de "la cuestión social" en los años veinte. Pero en Cautín, donde la ocupación militar y la colonización a fines del siglo XIX había dejado un legado de tierras en disputa con comunidades indígenas, la reacción a la Reforma Agraria y los proyectos emancipadores asociados a ella fue más combativa y 
defensiva. Esto quedó de manifiesto en la construcción de una narrativa nacionalista y anticomunista. Fue también más violenta debido a la amenaza a las ganancias familiares de las generaciones recientes. La violencia que se narra aquí estaba implícita en la lógica de un actor histórico que siempre había considerado que su papel consistía en defender la civilización europea contra la barbarie fronteriza. Como ya ha sido bien documentado por autores como José Bengoa, el territorio entre los ríos Bio Bio y Toltén mantuvo una sociedad indígena independiente hasta el proceso de la "pacificación” desarrollado entre las décadas de 1860 y $1880 .{ }^{1}$

Una serie de fuertes militares fueron establecidos en lugares como Traiguén y Temuco con el fin de hacer seguro el territorio para los colonos, muchos de los cuales habían sido activamente reclutados en Europa como una forma de civilizar la frontera y extender al sur el control del Estado chileno. Con el tiempo, los fuertes se convirtieron en regimientos que dominaban la vida cotidiana de las jóvenes ciudades fronterizas. Este rol civilizatorio asumido por los colonos (y en paralelo por los militares) quedó claramente reflejado en las acciones y los pensamientos de sus descendientes en los años 1960 y 1970, menos de un siglo después, como revelan algunos testimonios que se resumen más adelante. A la luz de ello, los terratenientes y el comportamiento en La Araucanía durante el periodo de la Reforma Agraria pueden ser vistos como una intensificación de la violencia histórica infligida sobre bandidos e indígenas en décadas anteriores tanto como una reacción contra la amenaza de revolución.

Mirando a lo largo del continente en el contexto de la Guerra Fría, los agricultores podían observar el giro hacia la izquierda que estaba teniendo lugar por todas partes como secuela de la Revolución Cubana, que parecía traer consigo la organización política de los pobres y el fin del viejo orden. En el caso de Cautín, el legado de la 'pacificación' llevó a los colonos agricultores a creer que 'sus propios' campesinos y las comunidades indígenas cercanas podrían mantenerse bajo control a través de una combinación de la sumisión tradicional y la anticuada coerción heredada de los vigilantes rurales de Hernán Trizano, matones voluntarios que patrullaban los territorios fronterizos recién conquistados entre los años 1890 y 1920, momento en que fueron incorporados al cuerpo de Carabineros. Sin embargo, esto no hizo menos preocupante el potencial de rebelión de los mapuche o mestizos: los terratenientes eran perfectamente conscientes del débil fundamento sobre el cual se basaba su riqueza duramente ganada, vulnerable a las fuerzas de la barbarie que el comunismo internacional tenía la habilidad de emplear en su propio beneficio para alcanzar fines totalitarios. Junto con este temor del retorno a la barbarie, la

1. Bengoa, J., Historia del pueblo mapuche, Santiago: Ediciones Sur, 5a edición, 1996. 
hostilidad tendía a focalizarse en aquellos que estaban en posición de influenciar a los más pobres y subvertir lo que ellos consideraban ser el orden social natural: una nueva clase media de activistas y empleados de gobierno.

\section{LA REVOLUCIÓN EN LIBERTAD Y LA REFORMA AGRARIA}

A través de la creación de asociaciones de vecinos, cooperativas campesinas y similares, la "revolución en libertad" de Eduardo Frei prometía traer justicia social y empoderamiento sin recurrir a la lucha de clases o al totalitarismo. Alentado por el éxito político, y bajo la influencia cada vez mayor de su ala izquierda, el Partido Demócrata Cristiano redactó la ley 16.040 de Reforma Agraria, aprobada en 1967, la que proponía poner fin al latifundismo a través de la expropiación de todos los grandes predios privados. De manera crucial, otras legislaciones extendieron el mecanismo que permitía a los trabajadores rurales establecer y unirse a sus propios sindicatos, introduciendo así, finalmente, la negociación colectiva en el campo, de la que se disfrutaba hacía décadas en las minas y fábricas. La doble perspectiva de la expropiación de la tierra y la acción colectiva potencialmente hostil que representaba esta legislación provocó una oposición generalizada por parte de los agricultores de Cautín, quienes ya se sentían amenazados por un "problema" mapuche en desarrollo y niveles hasta ese momento desconocidos de agitación política en el campo, extenso y de difícil acceso.

Los políticos y los dueños de los periódicos comprendían, aunque fuera sólo de manera intuitiva, algo que incluso Frei no veía: que por mucho que él pudiera demostrar en principio que su programa no estaba minando el capitalismo, sino más bien fortaleciéndolo, su gobierno sí minaba un sistema de dominación. No era suficiente para la clase terrateniente que se evitara el peligro de la revolución marxista y que todavía conservaran gran parte de su riqueza (las propuestas de Reforma Agraria contenían una generosa provisión para compensación y retención de tierras). Las medidas propuestas por la Democracia Cristiana implicaban que ya no podrían confiar en unos campesinos humildes que los seguirían lealmente y les aportarían con trabajo barato y votos en el Parlamento.

De manera creciente, a medida que avanzaba la década de los sesenta se hacía evidente que los terratenientes de Cautín se percibían atacados por todos los frentes. Las ganancias económicas venían declinando desde hace algún tiempo, el partido político al que muchos de ellos habían confiado sus votos para detener el marxismo se movía ideológicamente hacia la izquierda, una creciente clase media de burócratas se ganaba la vida expropiando sus tierras y las muestras del progresivo descontento mapuche eran acompañadas de rumores cada vez más verosímiles no 
sólo respecto a la antigua agitación comunista, sino también respecto a una incipiente actividad guerrillera. Nicanor Allende, Presidente del Consorcio de Agricultores del Sur, era un típico representante de la clase latifundista y sus declaraciones denotan un cambio importante en el discurso de los latifundistas respecto a la Reforma Agraria a partir de 1967, desde una línea defensiva y tecnocrática a otra que apelaba a sentimientos patrióticos. Él había comparado la "creación de tierra agrícola productiva" con "crear patria", sugiriendo una narrativa directamente opuesta a las narrativas populares de la nacionalidad que veía a la clase latifundista tradicional como la causa, más que la solución, del subdesarrollo. Exhortaba a sus colegas agricultores a "no dejarse intimidar por aceptar amenazas al progreso".

La formación del Partido Nacional en 1966 había sido un reflejo de la estrategia de la clase latifundista para ganar apoyo electoral al retratar a la oposición como antipatriota. Algunos de sus fundadores más importantes, como Víctor Carmine o Hardy Momberg, eran agricultores de Cautín. Durante la campaña electoral de 1969, en vísperas de los comicios parlamentarios, una inserción en El Diario Austral (único periódico diario de la provincia de Cautín, que los agricultores usaban para promocionar su punto de vista) incluyó una amarga respuesta a "el resentimiento, la procacidad y la soberbia que utilizaron [los representantes del Partido de la Democracia Cristiana] para denigrar la honrosa historia de nuestra patria" y de "tratar de justificar la destrucción material y el desquiciamiento espiritual que ha sufrido Chile bajo la 'Revolución en Libertad"'. Respondieron que "como chilenos, no podemos permitir el intento de denigrar una trayectoria histórica que a todos nos enorgullece y nos honra", juntando hechos como la victoria en la Guerra del Pacífico o la consolidación de un Estado soberano a la más alta producción agrícola en América Latina -este último logro protagonizado por ellos mismos. Con el fin de recuperar este avance histórico, la propaganda exhortaba a sus seguidores a "rebelarse contra la campaña de resignación y derrotismo". ${ }^{2}$ Una respuesta al llamado a la "rebelión" fue una acción de los líderes agrarios de Cautín y los miembros del Partido Nacional de Cautín, quienes bloquearon la carretera Panamericana en protesta por los bajos precios de la harina, descrita como parte de una estrategia nacional "totalmente sediciosa". Trece de ellos fueron arrestados y comenzaron a ser conocidos heroicamente entre sus partidarios como Los trece.

En las estrategias para ganar apoyo electoral y la realización de actos de desobediencia civil yacía, sin embargo, una estrategia aún más siniestra: la intimidación violenta de los campesinos y los empleados de gobierno involucrados en la ejecución de la política de Reforma Agraria. Una carta indignada firmada por cinco líderes de

2. El Diario Austral, 18 de noviembre de 1968. 
los sindicatos campesinos democratacristianos en la vecina provincial de Malleco acusaba a Óscar Schleyer, hacendado de Villarrica e intendente bajo el gobierno de Alessandri, y a Miguel Zerené de haber disparado a sus inquilinos. El último fue también acusado de ingresar a las oficinas de la CORA en estado de ebriedad con la intención de provocar una riña. De manera aún más dramática, un par de meses después, en la ciudad de Linares, el funcionario de la CORA, Hernán Mery, fue asesinado de un balazo mientras cumplía sus funciones. Víctor Carmine, diputado por Cautín, fue suspendido de su partido temporalmente por negarse a expresar condolencias oficiales por la muerte de Mery.

En muchos casos, el odio hacia los funcionarios de gobierno era extremo. Un aviso público contratado por la Asociación de Empleadores Agrícolas en El Diario Austral en respuesta a las acusaciones de violencia e intimidación hacia el equipo de la CORA, nos deja pocas dudas respecto a los niveles de hostilidad sufridos por estos últimos en los meses previos a la toma de poder por parte de la Unidad Popular. Una carta firmada por varias asociaciones de terratenientes locales vinculaba el sistema de expropiaciones a las prácticas de los regímenes totalitarios. Es interesante advertir que la política de gobierno ya había sido comparada a un "régimen totalitario" algún tiempo antes de que la posibilidad de un presidente marxista en Chile fuera inminente. Después de criticar la mala productividad de los predios administrados por la CORA, concluía, en letras mayúsculas: 'La historia dirá quiénes son los malos chilenos: si nosotros los empleadores agrícolas que con nuestro esfuerzo por generaciones hemos hecho grande esta zona o estos nuevos dioses de corta vida, expoliadores del trabajo ajeno, mentirosos por costumbre y sembradores de falsas ilusiones. ${ }^{3}$ No es difícil imaginar cómo reaccionaría esa gente en los años y meses siguientes, cuando a la victoria de Salvador Allende le siguieron rumores de tomas armadas y se generalizaron las movilizaciones masivas de las comunidades mapuche.

\section{EL "CAUTINAZO”}

No cabe duda de que la situación en Cautín presentaba uno de los primeros y mayores desafíos para la vía chilena al socialismo de la Unidad Popular, una

3. El Diario Austral, 26 de marzo de 1970. La carta está firmada por Omar Cancino, presidente del Sindicato de Pequeños Propietarios Agrícolas de Lautaro; Carlos Kulenkampff, presidente de la Federación de Sindicatos de Empleadores Agrícolas de Bio Bio; Alberto Levy, presidente de la Federación de Sindicatos de Empleadores de Malleco, y Pablo Goebel, presidente de la Federación de Sindicatos de Empleadores Agrícolas de Cautín. 
transición proyectada hacia el sistema socialista que ocurriría completamente dentro de la legalidad de los acuerdos políticos existentes. Una de las principales razones para ello era que la legislación de Reforma Agraria no tomó en cuenta las disputas de tierra en desarrollo entre los agricultores y las comunidades mapuche, las cuales ya se contaban por cientos. Esto había ocurrido como consecuencia de la toma fraudulenta de tierras de las comunidades por los fundos adyacentes, tierras a menudo vendidas posteriormente, lo que creaba situaciones en las que ambas partes podían reclamar derecho legal sobre el predio en cuestión. A consecuencia de esto los juzgados de indios tramitaron nada menos que 1.434 disputas de tierras en la década entre 1961 y 19714. No debería sorprendernos que aquellas comunidades no solamente dieran la bienvenida a la Reforma Agraria cuando por fin llegó, sino que la desbordarían, empujándola mucho más allá de los límites contemplados por el gobierno. Un artículo de Punto Final analiza nueve de las tomas de tierra protagonizadas en Cautín por comunidades mapuches durante los primeros dos meses de la presidencia de Allende. Todas ellas habían perdido tierras, sumando 100 hectáreas o más durante los 40 años previos. En el caso del bien nombrado fundo "Poco a Poco", por ejemplo, una adquisición original de 20 hectáreas a principios del siglo XX había crecido a 130 hectáreas solamente a través de la usurpación de tierras mapuche. ${ }^{5}$

Esta situación fue aprovechada por el extraparlamentario Movimiento de Izquierda Revolucionaria (MIR), el que no compartía la confianza del gobierno de Allende en la vía chilena. De hecho, el MIR, o más específicamente su frente campesino, el Movimiento Campesino Revolucionario (MCR), ya había apuntado a Cautín como una zona en que la revolución estaba a punto de estallar. Frustrados con el lento ritmo del cambio y escépticos respecto a la capacidad de instituciones democráticas burguesas -como ellos las calificaban- para dar lugar a la revolución de clases, su estrategia consistió en facilitar la toma directa de los predios, con especial énfasis en las comunidades mapuche y sus crecientes demandas. Aunque desde el año 1967 habían aparecido menciones a su presencia y rumores de actividad guerrillera en El Diario Austral, sus verdaderos logros en la movilización llegaron en el momento inmediatamente posterior a la victoria de Allende y pueden ser medidos por el número de tomas que tuvieron lugar entre los meses de noviembre de 1970 y abril de 1971: unas 70, representando alrededor de $12 \%$ de la cifra nacional. ${ }^{6}$

4. Redondo, Jesús A., "Las tomas de fundos en la provincial de Cautín (Chile), 1967-1973." Cuadernos de Historia 42, Departamento de Ciencias Históricas, Universidad de Chile, junio 2015, p.161.

5. Punto Final, no. 122, January 19, 1971, "La derecha conspira para detener la refoma agraria".

6. Lehmann, D., Land Reform in Chile 1965-1972. Tesis. DPhil, University of Oxford, 1974, p.185. 
Bajo el titular 'Territorio Mirista', la descripción que hacía El Diario Austral de la situación puede leerse como una mezcla de preocupación real de que Cautín se transformara en una especie de segunda Cuba y un cómico desdén hacia los jóvenes idealistas de clase media que últimamente se encontraban por todas partes en las zonas apartadas del campo. "Consumiendo unas ocho vacas diarias, tomando el sol en cómodas poltronas -como típicos veraneantes- y guapeando a lo largo y ancho de la zona agrícola de la provincia de Cautín, los miristas son los nuevos dueños y señores de la región", anunciaba con desdén un periodista en marzo de 1971. Pero conllevaba un aviso serio: "La actividad de estos grupos, en su mayoría compuestos por jóvenes barbudos, es intensa y se concreta a la "concientización" de los campesinos, en su mayor parte mapuches, para mantenerlos constantemente entrenados para la acción."’

No fueron solamente los mapuche los que se politizaron a consecuencia de una promesa de redistribución masiva de tierras y de poder. Tampoco resulta sorprendente que hubiese una politización sustancial por parte de los agricultores. Su reacción era de ponerse a la ofensiva, lo que logró como consecuencia un resurgir de las actitudes, opiniones y creencias que, como señala Fernando Pairican en un libro reciente, los condujo a desempolvar las escopetas -si es que se las habían guardado alguna vez- que sus padres habían usado en los años siguientes a la ocupación de La Araucanía. ${ }^{8}$

\section{LOS COLONOS DEFIENDEN LOS LOGROS DE SUS PADRES}

Las historias de vida y los testimonios de los terratenientes que vivieron la Reforma Agraria dejan claro el vínculo entre la defensa de la tradición familiar, la conciencia de una misión civilizatoria y la ideología anticomunista. Jaime Baier, nacido en 1943, es un exitoso terrateniente que desciende de inmigrantes alemanes. Él relataba cómo su familia había llegado a comienzos del siglo XX, dando énfasis a una importante ética del trabajo. Contó cómo su familia había trabajado tranquila durante $60 \mathrm{u}$ 80 años, pero que él junto a sus hermanos "se encontró con este problema de importación de ideas políticas". Al no poder heredar suficiente tierra familiar, Baier había comprado un fundo de unas 1.500 hectáreas cerca de Temuco cuando llegó la Reforma Agraria de Frei. Según su testimonio, los campesinos que tomaron su tierra mostraron su ignorancia matando varios animales. "Mataron quince cabras para alimentar a sus perros. Luego cogieron cuatro o cinco novillos para hacer un

7. El Diario Austral, 24 de marzo de 1971.

8. Pairican Padilla, F., La rebelión del movimiento mapuche, 1990-2013 Santiago: Pehuén, 2014, p.43. 
asado", me dijo, una queja típica de todos los que perdieron capital y tierra en las tomas. Se quejaba de que los nuevos ocupantes de la tierra no trabajaban dada la facilidad que tenían para girar dinero regalado por el gobierno. Sus opiniones sobre la Reforma son ilustrativas de la mentalidad de los colonos: "Yo creo que esto fue una utopía", continuaba. "La cultura y la genética [de los pobres] no permitía vencer el hambre y la pobreza de una gente que no quería trabajar. El flojo nunca superará la pobreza. Prefiere ser arreado. Maltratado, pero que tiene la protección de un patrón que le paga aunque sea mal." Terminaba justificando el evidente rol civilizatorio de su familia. "Nosotros sencillamente trabajábamos y entendíamos un poco más de economía y de mercado y de producción porque habíamos leído y éramos más cultos".?

Germán Becker, alcalde de Temuco durante la mayor parte del periodo de Reforma Agraria y también descendiente de alemanes, era un agricultor de segunda generación de inmigrantes, dueño de un predio de 950 hectáreas y miembro de aquella facción del Partido Radical que se oponía a Allende. Los años del gobierno de la Unidad Popular fueron particularmente difíciles para la familia Becker: en abril de 1971 Germán Becker había perdido la alcaldía de Temuco en favor de un obrero socialista, Carlos Riffo, debido a un tecnicismo; en julio, su hermano Osvaldo había sido hospitalizado debido a una crisis nerviosa cuando su fundo fue expropiado, $y$ había muerto su madre viuda, Augusta Baechler, quien, siendo niña, había llegado con su padre como "colonizadores de la frontera". El Diario Austral sugirió que ella había muerto de pena al presenciar los tumultuosos acontecimientos que la rodeaban. Su obituario reafirma la importancia de la narrativa sobre los colonos en la antigua frontera. Este afirma que Augusta, junto a su futuro esposo, Óscar Becker, viajaban del extranjero para colonizar el sur, respondiendo a un llamado del gobierno de Chile. La necrología describió las duras condiciones de vida cuando llegaban a finales del siglo XIX: "Buscaban una actividad dura, sacrificada, en que se debe empezar por desbrozar los árboles, limpiar las tierras de troncos, cercar, e iniciar el largo camino para obtener campos de producción, en lucha constante contra ... una serie de enemigos, entre los que cuentan los propios hombres."10 Claramente estos "hombres" eran los bandidos y los indios que habitaban en la peligrosa frontera a la que ellos habían llegado para establecerse y trabajar la tierra.

El periodista e historiador británico Alistair Horne entrevistó a Germán Becker en el idioma alemán que ambos dominaba bien, en enero de 1971, mientras investigaba para su conocido libro de esa época sobre el periodo de Allende, A Small Earthquake

9. Entrevista con Jaime Baier, Temuco, 17 de noviembre de 2009.

10. El Diario Austral, 3 de julio de 1971. 
in Chile (Pequeño terremoto en Chile). Parecía evidente que debido al número creciente de tomas de terreno, Cautín se había instalado rápidamente al centro de la política nacional. Alegando que Carabineros había recibido instrucciones específicas para no defender a los propietarios frente al MIR, confidenció que ellos estaban "muy tristes" con el rol que debían jugar. Sus comentarios sobre los mapuche y sobre el país de origen de su familia parece demostrar que la preocupación respecto a las fuerzas de la barbarie era mayor que aquella preocupación sobre las fuerzas ideológicas de izquierda. Horne escribió que Becker deploraba el daño que los agitadores estaban causando entre los mapuche, frente a quienes demostraba poca admiración. Sus críticas a los mapuche reflejan claramente el discurso civilizatorio que alentaba a sus padres. Horne resume sus opiniones: "Nunca se han interesado mucho en limpiar el territorio virgen; ellos solo crían ovejas en pequeños paños de tierra dispersa, e incluso pocos trabajan adecuadamente. La ebriedad es un problema terrible". Luego, cita directamente a Becker hablando de los beneficios de su propia cultura: "Nosotros, los alemanes, somos muy disciplinados, así que al menos allí está funcionando el komunismus... Aquí todos quieren ganar pero nadie quiere trabajar. En el pasado, los chilenos nunca encontraron el modo de hacer trabajar a la gente, así que... el futuro será peor aquí que en Alemania Oriental”. Terminaba la conversación hablando del pasado y futuro de su familia. "Todos trabajamos extraordinariamente duro... levantamos todo de la nada”, afirmó, antes de lamentar que la política del gobierno y la vuelta al desorden significara que cada uno de sus siete hijos se vieran obligados a salir de Chile. ${ }^{11}$

\section{RESISTENCIA ARMADA}

Sin embargo, evidentemente no todos quienes se quedaron y perdieron con el gobierno de Allende tuvieron la posibilidad de irse. Otro joven y destacado terrateniente y político de Cautín, Víctor Carmine, recuerda las colas en el aeropuerto para dejar el país inmediatamente después de la elección de 1970. Su abuelo paterno era un suizo-italiano que colonizó terrenos en la zona de Ercilla en 1884. Carmine manifiesta su temor en el tiempo de la Reforma Agraria como una amenaza existencial. Recuerda cómo agricultores como él fueron tachados de 'kulaks' -los campesinos rusos destrozados por Stalin- y cómo a consecuencia esperaban un destino semejante. Aún parece convencido de que "íbamos a ser absolutamente eliminados, primero como sujetos económicos iy algunos como

11. Horne, A., Small Earthquake in Chile Londres: Papermac, 1990 pp.174-182. 
sujetos personales!". ${ }^{12}$ Sentía que las instituciones legales y del Estado habían perdido legitimidad debido a lo que él percibía como el sesgo ideológico de estas. En el caso de Carmine, a diferencia de Becker, la desesperación se transformó en una determinación para luchar.

Su testimonio acerca de la retoma o "devolución” del fundo Rucalán en Carahue en la Noche Buena de 1970, ilustra la determinación, organización y logística que la clase agricultora había ya desarrollado en Cautín al comienzo de la presidencia de Allende. El fundo había sufrido una fuerte toma por parte de los miembros de la vecina comunidad mapuche y activistas del MCR. De acuerdo a informes sobre el evento, la casa familiar fue rodeada al amanecer y se concedió veinte minutos a sus ocupantes para desalojar sus dependencias. Al igual que los amigos y compañeros del Partido Nacional, como Carlos Podlech (abogado y diputado como él), la pertenencia al Parlamento y la profesión jurídica no era un obstáculo para el uso de la resistencia organizada y armada. Aunque en la actualidad se distancia de sus acciones en aquellos tiempos, contó con cierto orgullo cómo él junto a unos 80 voluntarios se organizaron para realizar la primera retoma de la Reforma Agraria en Chile. "Sencillamente dijimos 'vamos a retomar la cosa'. Entonces nos organizamos. Qué se yo, seríamos unos 80 voluntarios y nos fuimos y retomamos el fundo a tiro limpio." 13 Deja en claro que las vidas de los campesinos y las familias mapuche que disfrutaban de la fiesta de Navidad eran despreciadas, como si se tratara de una manada de animales extraviados. Según Carmine era el aparato del Estado, a través de sus leyes y sus acciones punitivas, el que se representa como si estuviera actuando ilegalmente por atreverse a investigar el acontecimiento.

Siguieron otros episodios protagonizados por armas de fuego. Un memorándum de la Intendencia dirigido al Ministro de Agricultura señalaba que las acciones de Carmine eran sólo una parte de un esfuerzo concertado para oponerse a la reforma en Cautín: "estos actos de matonaje persiguen crear, evidentemente, un clima de inseguridad y de confusión; son desórdenes y actos de violencia destinados a alterar la tranquilidad pública ... para entender mejor el ánimo que inspiró la conducta de Carmine es preciso considerar la situación especial que vive esta provincia en relación con los problemas del agro." A modo de ejemplo, el informe habla de la generación de rumores diseñados para crear una "verdadera sicosis" en algunos barrios, tales como falsos rumores de expropiación, o el avistamiento de "cubanos" en los alrededores, o actos que buscaban crear un clima de temor e inseguridad ${ }^{14}$.

12. Entrevista con Víctor Carmine, Temuco, 19 de diciembre de 2009.

13. Ibid.

14. Oficios despachados 1971, Archivo de la Intendencia de Cautín, carpeta 336 'Caso Carmine'. 
No pasaría mucho tiempo antes de que el Partido Nacional sumara un mártir a la causa. El 19 de abril de 1971, un joven miembro del partido, Rolando Matus, fue muerto de un tiro defendiendo su tierra de miristas en Curarrehue, en el campo de Pucón. Inmediatamente descrito como "mártir de Cautín” el día de su funeral, no tomó mucho tiempo para que los miembros armados del Partido Nacional formaran el Comando Rolando Matus, una organización paramilitar que trabajaba para "defender" la tierra de los extremistas y los mapuche. Sin embargo, a los ojos de algunos no estaban simplemente defendiendo la propiedad, sino el propio concepto de civilización. En una ocasión, el candidato del Partido Nacional Miguel Huerta incluso comparó a Matus con 'El Cid, quien [también] ganará su batalla para preservar la civilización cristiana'. ${ }^{15}$ Tal lucha estaba causando muerte y daños a fines de 1971. El Diario Austral vinculaba incidentes en los fundos de Huilío y Chesque, que causaban protestas a nivel nacional por la muerte de varios mapuches, a la historia de la frontera y la Guerra de Arauco, mediante la cual los conquistadores intentaron por primera vez someter al pueblo mapuche. Bajo el titular "La lucha por el Sur" afirmaba que "no cabe duda de que la agitación en los campos del sur encierra un complejo de peligro mucho mayor que el de la zona central." ". Hacía alusión al aventurero francés Orelie Antoine, quien había ofrecido convertirse en un rey que guiaría a los mapuche en su lucha contra el recién independizado Chile a comienzos del siglo XIX, sugiriendo que los "nuevos colonizadores" en el siglo XX serían los revolucionarios pagados por Moscú, Pekín o La Habana. Informes de testigos parecían corroborar rumores sobre campos de entrenamiento guerrillero esparcidos en toda el área, especialmente en las vastas reservas forestales en Panguipulli, donde el ya mítico comandante Pepe era ampliamente considerado como el equivalente chileno del Che Guevara.

Trabajando junto al Comando Rolando Matus existía un sector fuerte de Patria y Libertad. Este grupo desarrolló una estrategia basada en numerosos actos terroristas de baja intensidad tales como cortes de suministro eléctrico, colocación de bombas caseras o el descarrilamiento de trenes, diseñados para crear miedo y confusión entre la población. Casi todos los testimonios sobre Cautín durante la época de la Unidad Popular coinciden en su memoria de un Patria y Libertad activo y ubicuo. Solamente en el mes de agosto de 1973 hubo unos 60 ataques atribuibles al grupo, algo así como $20 \%$ de la cifra nacional. ${ }^{17}$ Según muchos informes, hallaron una clase terrateniente altamente afín a su ideología neo-fascista que hizo hincapié en su

15. El Diario Austral, 4 de diciembre de 1971.

16. El Diario Austral, 2 de diciembre de 1971.

17. Harmer, T. Allende's Chile and the Inter-American Cold War North Carolina: University of North Carolina Press, 2011, p.236. 
postura anti-marxista y de renovación de la patria. Eligieron a Temuco para convocar una conferencia nacional de delegados miembros de Patria y Libertad durante mayo de 1973, siendo esta además la ciudad donde sus directores anunciaban su regreso del exilio, informado a través de El Diario Austral el 10 de septiembre de 1973.

\section{LA INTENDENCIA DE CAUTÍN ENTRE LA ESPADA Y LA PARED}

No fueron sólo los revolucionarios románticos del MIR los que provocaron la ira de la clase terrateniente local y sus aliados militares, tal como había dejado en claro la trágica historia del Intendente de Cautín, miembro de la Unidad Popular y más tarde diputado por el Partido Radical. De acuerdo a los testimonios, Gastón Lobos, "masón, bombero y radical", era un miembro influyente de su comunidad en Pitrufquén, y tenía reputación por ayudar a los menos favorecidos. La Unidad Popular asignó el gobierno provincial de Cautín al Partido Radical, probablemente debido a que como elemento más moderado se adaptaba mejor a las complejas y delicadas negociaciones que inevitablemente surgirían en una región polarizada entre una clase terrateniente recalcitrante y un campesinado indígena hostil.

El gran volumen de documentos en los archivos de la Intendencia relativos a las disputas territoriales da testimonio de la casi imposible situación en la que se encontraba Lobos desde el principio de su mandato hasta el final, en noviembre de 1972. Como representante del Presidente en la provincia, estaba encargado de supervisar la ejecución legal y rápida de la Reforma Agraria, pero se encontraba constantemente atrapado entre la fuerza arrolladora de las invasiones ilegales de tierras y la oposición inflexible de los terratenientes organizados.

Lobos demostró tener una mano firme con la extrema izquierda rechazando dar tribuna al MIR y destituyendo de sus puestos a médicos y empleados de gobierno si sus opiniones o acciones amenazaban la credibilidad del mismo. Durante la visita de Fidel Castro a Chile a fines de 1971, Lobos logró persuadir a Allende para excluir la zona de Cautín del itinerario, argumentando que su presencia podría desencadenar numerosos conflictos latentes. La esposa de Lobos, Irma Felber, reflexionaba sobre el enojo y la frustración de su esposo por los excesos y la inmadurez mostrados por los miembros del MIR y sectores del Partido Socialista, a quienes acusó de socavar la legitimidad del proyecto de Reforma Agraria. En declaraciones a El Diario Austral, Lobos declaró: "hemos elegido la vía más larga al socialismo, la vía democrática. Sin embargo, un número de nuestros compañeros, especialmente aquellos con menos cultura, piensa que la elección de Allende representa una licencia para ocupar tierras y fundos." ${ }^{18}$

18. El Diario Austral, 14 de febrero de 1971. 
Felber reconocía que los altos niveles de pobreza y la desesperación entre la población hicieron popular la estrategia de acción directa de la extrema izquierda en los sectores más desposeídos, a quienes casi literalmente se prometió "pan hoy". Ella admitía que los trabajadores del campo a menudo eran tratados de peor manera que los animales que cuidaban. Como ejemplo, mencionaba la costumbre de dar la leche de vaca a los cerdos mientras quienes cuidaban los rebaños todo el día no tenían nada para sus hijos. ${ }^{19}$

A pesar de la energía, moderación y habilidades diplomáticas demostradas por Lobos -quien ganaría un asiento en el Parlamento en las elecciones de 1973- su destino eventual reflejaba el de otras personas víctimas de un ejército vengativo. El 13 de septiembre de 1973 Lobos fue arrestado y llevado al regimiento Tucapel, donde se le afeitó el cabello. Luego, fue conducido por el centro de Temuco de manera indigna antes de ser puesto bajo arresto domiciliario hasta el 5 de octubre, fecha en que fue nuevamente detenido. De acuerdo al blog escrito por la Fundación Gastón Lobos se informó que fue puesto en libertad el día 11 de octubre, justo veinte minutos antes del toque de queda, pero no llegó a su casa. Desde entonces, nunca se le volvió a ver.

\section{LA RECONQUISTA MILITAR DE CAUTÍN}

Dados estos antecedentes, no es sorprendente que Cautín ya estuviera bajo ocupación militar efectiva en el año 1973 muchos días antes del 11 de septiembre. A comienzos de mes, la prensa reportaba que una operación combinada entre el Ejército, la Fuerza Aérea y Carabineros en el Centro de Reforma Agraria y el Asentamiento Jorge Fernández había concluido con 27 arrestos y el hallazgo de granadas, bombas, dinamita y material destinado a la fabricación de explosivos. También reportaba que los activistas del MIR habían huido del área, especulando que "se comenta que la operación revelará la actividad de la guerrilla en una escala insospechada" 20 añadiendo que los campesinos habían denunciado una suerte de tiranía local ejercida por activistas del MIR, quienes los obligaban a tomar parte en la actividad revolucionaria. Las fotografías de las portadas de los siguientes días mostraban al coronel Pablo Iturriaga, coordinador de la operación y muy pronto intendente designado por la Junta Militar, exhibiendo a los periodistas lo que él describía como "armamento antitanque", el que se mostraba para confirmar que se estaban haciendo los preparativos para algún tipo de guerra total. Una vez más

19. Entrevista a Irma Felber, Temuco, 13 de mayo de 2010.

20. El Diario Austral, 5 de septiembre de 1973. 
aquí hay evidencia de que se hacía aparecer al colectivo campesino como si fuera una fuerza militar. $\mathrm{Al}$ inspeccionar de más cerca estos artefactos se parecen más a objetos que uno podría encontrar en la cocina que otros para ser lanzados a tanques en el campo de batalla. El informe del funcionario de la CORA Mario Rivas afirmó que se trataba de bombas caseras hechas con ollas de cocina, y la idea de que podían ser usadas contra tanques era ridícula. ${ }^{21}$

El Ejército ya había allanado las oficinas de la CORA en agosto de 1973. Rivas describía la humillación sufrida por los aproximadamente 20 empleados que fueron encañonados mientras los soldados revisaban las oficinas. Cuando el director protestó por este tratamiento a su equipo, se le ordenó, a punta de cañón, que permaneciera boca abajo en el suelo. El día de la operación, el intendente Sergio Fonseca le pidió a Rivas acompañar a la patrulla militar. Ya había notado la fría actitud de los soldados hacia él cuando, en Carahue, Rivas recibió la orden de abandonar el vehículo debido a la naturaleza estrictamente militar de la operación. Sin embargo, logró conseguir un camión para continuar los 20 o 30 kilómetros hacia la costa. A su llegada se impresionó al ver campesinos atados a los árboles, obligados a confesar la posesión de armas mientras eran azotados. Esto llevó a Rivas a darse cuenta de dos cosas: que el intendente no tenía ninguna autoridad efectiva en la zona del campo de la provincia (donde el Ejército tenía rienda suelta) y que los ideólogos dentro del gobierno de la Unidad Popular que defendían abiertamente el método de la "lucha armada" - como el secretario del Partido Socialista, Altamirano- no tenían ni idea de lo unilateral que era el conflicto en el campo de Cautín. Más tarde, Rivas señaló que quienes más habían perdido con la Reforma Agraria habían sido los descendientes de colonos extranjeros, en particular los de origen alemán. Fueron ellos los que habían "generado el proceso" que llevó a la caída de Allende.

Estos hechos no eran un secreto para el público chileno que tenía acceso a la televisión. Rivas invitó a los periodistas de Televisión Nacional a hacer un programa exponiendo los acontecimientos, que fue transmitido el 6 de septiembre. Las reacciones en El Diario Austral demuestran los niveles de histeria y de odio con que habían sido azotados en este tiempo. Una inserción de la Asociación de Contadores de Cautín declaró que las entrevistas fueron 'prefabricadas', proclamando furiosamente que "no se atrevan a tocar nuestras Fuerzas Armadas, cerdos. Ellos son sangre de nuestra sangre, santuario de las tradiciones de nuestra tierra, espejo de nuestra nacionalidad, custodios del honor y dignidad de Chile". ${ }^{22}$ Sin embargo, antes de que se pudiera verificar la veracidad de los hechos y de tener un debate

21. Entrevista con Mario Rivas, Temuco, 2 de noviembre de 2009.

22. El Diario Austral, 7 de septiembre de 1973. 
serio, Cautín, junto con el resto de Chile, se encontró bajo ocupación militar a gran escala.

El día del golpe, los diputados del Partido Nacional Víctor Carmine y Hardy Momberg, junto con el ex alcalde Germán Becker, se presentaron en el Regimiento Tucapel en persona, ofreciéndose a ayudar en lo que presumiblemente pensaban sería un retorno al viejo orden. En el evento, ellos habían sido cortésmente apartados. Carmine describe lo que sucedió después de haber hablado en la radio en apoyo al golpe. "Queríamos ayudar a combatir del lado de las Fuerzas Armadas. De inmediato fuimos al Regimiento y le dijimos al Coronel Iturriaga: 'estamos aquí, estamos a sus órdenes, apoyamos el golpe, así que si nos quieren para algo, estamos aquí a su lado'. Dijo, 'gracias por estar de nuestro lado. Si los necesitamos para cualquier cosa, estaremos en contacto. Mientras tanto, todos pueden ir a casa.' ¡Nos envió a casa! Y por supuesto tomé unos tragos de whisky para celebrar lo que había sucedido. Pensaba que era maravilloso." 23

Sin embargo, el régimen militar no restituyó el antiguo statu quo. Muchos terratenientes, entre ellos algunos de los entrevistados para esta investigación, se sintieron decepcionados al saber que simplemente no volverían a recuperar sus antiguas posesiones donde había organizaciones que funcionaban bien. Una CORA purgada políticamente continuó funcionando hasta 1978, dando títulos de tierras a campesinos individuales que no habían estado políticamente activos o involucrados en tomas. Finalmente, como es bien sabido, la falta de apoyo y crédito forzó a muchos beneficiarios a vender, lo que resultó en una reconcentración de la tierra, particularmente notable en el caso del sector forestal. A consecuencia de esto y de la represión, la época de la dictadura vería un resurgir de la demanda territorial e identitaria indígena, pero no del movimiento campesino. Lo que los agricultores de Cautín habían ayudado a lograr fue una re-militarización de la frontera y un aparente regreso a la jerarquía, la paz social y la seguridad que sus antepasados habían disfrutado en décadas anteriores.

\section{CONCLUSIONES}

Durante los años de la Reforma Agraria en Cautín se acentuó un conflicto de lenta combustión que había estado en progreso desde la pacificación, trayendo una respuesta violenta y nacionalista por parte de los colonos de la región. Este estudio de caso reafirma que la derecha autoritaria en Chile estaba bien organizada y había desarrollado una clara ideología incluso antes de que Allende llegara al poder. La

23. Entrevista a Víctor Carmine, Temuco, 19 de diciembre de 2009. 
determinación de los terratenientes colonizadores de defender sus fundos y su poder político se fortaleció durante los años de gobierno de la Unidad Popular, por un lado debido a los esfuerzos decididos del MCR de utilizar los conflictos latentes de la región para su agenda revolucionaria, y por otro, debido a la falta de recursos a disposición de la administración local para hacer frente al volumen de toma de tierras y de recuperaciones que ocurrían simultáneamente en un territorio extenso y mal conectado. Para los terratenientes y la derecha autoritaria de Cautín, la oposición activa a la creciente ola de empoderamiento popular era más que simplemente una reacción al miedo aferrándose a un pasado mítico de respeto y paz social. Se mostraron capaces de innovar, crear estrategia e imitar al enemigo con el fin de allanar el camino para la refundación de una nación según su propia "narrativa nacional", basada en el discurso de la civilización versus la barbarie. Esta narración estaba implícita, entre otras cosas, en las comparaciones entre la oligarquía latinoamericana y los dictadores ibéricos o los imperios greco-romanos en la prensa local. A nivel práctico, fue capaz de combinar su poder sobre la infraestructura y la opinión pública local para deslegitimar el proyecto de modernización izquierdista, combinándolo con la desobediencia y la confrontación violenta.

La historia relativamente reciente de la ocupación de la tierra y la reducción de las comunidades indígenas en Cautín -todavía presente en el ámbito de la memoria viva- significó que la paz y la estabilidad que existieron durante siglos de manera aparente en las haciendas del valle central nunca podrían darse por sentadas en medio de la pobreza y el caos administrativo de las provincias fronterizas. La clase terrateniente en esta provincia compartía la preocupación de los hacendados del valle central respecto a la imposición de ideologías 'no chilenas' de conflicto de clases y redistribución material. Estas ideologías eran percibidas como provenientes de los antagonistas -considerados como enemigos de la nación- que debían ser derrotados. A diferencia de sus aliados de clase más al norte, sin embargo, los terratenientes de Cautín poseían una ética de trabajo pionera que implicaba defender hasta la muerte los avances de sus padres y abuelos de la siempre presente amenaza de la barbarie. Quizás se podría decir que mientras los terratenientes tradicionales del valle central fundaron su legitimidad en la misión divina de la conquista española, los terratenientes al sur del río Bio Bio fundaron la suya en el espíritu pionero, el trabajo y el sacrificio de sus antepasados.

Si bien temían a las fuerzas de la barbarie, era la clase media reformista la que realmente les molestaba. Cuando funcionarios jóvenes e idealistas vinieron a sindicalizar a sus trabajadores y dividir sus tierras, o cuando los estudiantes imbuidos de ideas revolucionarias venían de Concepción para infiltrarse en las comunidades mapuche y ocupar sus tierras, sentían una indignación que requería una respuesta colectiva. Los columnistas de El Diario Austral demuestran claramente cómo la 
antigua ideología de civilización versus barbarie se adaptó al discurso anticomunista de la Guerra Fría. La resistencia violenta a la modernización fue coordinada por organizaciones como el Comando Rolando Matus o Patria y Libertad, cuyas acciones anticipaban el golpe militar de septiembre de 1973. De hecho, la paranoia de los "campos de entrenamiento de guerrillas", combinada con la ley de control de armas, aseguraban la posibilidad de que las Fuerzas Armadas ya estuvieran torturando a los campesinos y desmantelando las unidades de producción agrícola semanas antes del bombardeo a La Moneda. En este sentido, la reconquista de la frontera y el retorno de la sociedad militarizada en Cautín anticiparon el destino que iba a acontecer en todo Chile.

Este examen minucioso de las raíces históricas, el pensamiento y acciones de la derecha en Cautín, ha puesto atención sobre las circunstancias especiales de la región fronteriza. Estas incluyen disputas no resueltas sobre la tierra, una mayor sensación de vulnerabilidad entre los terratenientes principalmente descendientes de inmigrantes y un vínculo más evidente entre las Fuerzas Armadas y la clase social dominante. Fue en la frontera donde la sociedad se mantuvo dominada por los valores marciales arraigados en la pacificación -incluso quizás en la guerra de Arauco del siglo XVI. Era aquí también donde una solución militar al conflicto social parecía más lógica y natural. También reveló continuidad en la brutalidad y el triunfalismo de ambos sectores. Sin embargo, estos hallazgos han revelado al mismo tiempo aspectos ocultos de la dinámica histórica del poder a nivel nacional, contribuyendo a comprender por qué el proyecto de empoderamiento popular fracasó. Porque en Cautín, tal vez más que en cualquier otra provincia, el sistema jerárquico de valores y el verdadero poder de la derecha chilena, que se hallaba bajo la delgada capa de institucionalidad democrática estable, era más evidente que en otras partes. La lucha de la civilización contra la barbarie en la frontera agregó un elemento de violencia al opresivo "peso de la noche" -la frase que condensa el liberalismo autoritario de Diego Portales que había dominado la política de la élite en Chile durante gran parte de su historia- que había continuado aplastando al campesinado chileno hasta la llegada de la Reforma Agraria. En esta, la más indígena de todas las provincias chilenas, el golpe militar del 11 de septiembre de 1973 aparecía de alguna manera como una continuación de la violencia fronteriza implícita o explícita que había estado ocurriendo durante décadas. La región había visto a las Fuerzas Armadas, tradicionales garantes del orden en la frontera, tomando el control de facto de la región algún tiempo antes de la toma del poder por parte de los militares a nivel nacional. Como ha sugerido el poeta y escritor mapuche Elicura Chihuailaf, si 1883 marcó la pacificación del territorio mapuche, 1973 marcó la pacificación de Chile en su conjunto. 


\section{REFERENCIAS}

Bengoa, José. Historia del pueblo mapuche. Santiago: Ediciones Sur, 5a edición, 1996.

. La comunidad fragmentada. Nación y desigualdad en Chile. Santiago: Catalonia ediciones, 2009.

Comité Interamericano de Desarollo Agrícola (CIDA). Tenencia de la tierra y el desarrollo económico. Santiago: CIDA, 1966.

Correa, Martín; Molina, Raúl; Yáñez Nancy. La Reforma Agraria y las tierras mapuches, Chile 1962-1975. Santiago: LOM, 2005.

Correa Sutil, Sofía. Con las riendas del poder. La derecha chilena en el siglo XX. Editorial Sudamericana, Santiago, 2004.

Crow, Joanna. The Mapuche in Modern Chile: A Cultural History. University of Florida Press, 2013.

Grandin, Greg \& Joseph, Gilbert M. (editores). A century of revolution: insurgent and counterinsurgent violence during Latin America's long cold war. Durham: Duke University Press, 2010.

Hennessy, Alistair. The Frontier in Latin American History. London: Edward Arnold, 1978.

Horne, Alistair. Small Earthquake in Chile. London: Papermac, 1990.

Lehmann David. Land Reform in Chile 1965-1972. DPhil, University of Oxford, 1974.

Loveman, Brian. Struggle in the Countryside: Politics and Rural Labor in Chile, 1919-1973. Bloomington: Indiana University Press, 1976.

Mallon, Florencia E., La sangre del copihue: la comunidad mapuche de Nicolás Ailío y el Estado chileno 1906-2001. (Santiago: LOM, 2004).

Pairican Padilla, F., La rebelión del movimiento mapuche, 1990-2013 Santiago: Pehuén, 2014.

Pino Zapata, Eduardo. Historia de Temuco. Biografía de la capital de la Frontera. Temuco: Ediciones Universidad de la Frontera, 1998.

Pinto, Jorge. El Bandolerismo de la Frontera (1880-1920). Temuco: Ediciones Universidad de la Frontera, 1985.

Steenland, Kyle. Agrarian Reform under Allende. University of New Mexico Press, 1977.

Tinsman, Heidi. La tierra para el que la trabaja. Santiago: LOM, 2009. 


\section{FUENTES}

\section{Archivos y registros públicos}

Archivo Nacional de Chile (Biblioteca Nacional, Santiago)

Archivo de la Intendencia de Cautín (Archivo Regional de la Araucanía, Temuco)

Archivo de la Corporación de Reforma Agraria (Servicio Agrícola y Ganadero, Santiago)

Archivo del Ministerio de Agricultura (Archivo Nacional, Santiago)

\section{Publicaciones periódicas y diarios}

Diario Austral (Temuco) 1967-1973

Ercilla (Santiago) 1973

La Nación (Santiago) 1970-1973

Punto Final (Santiago) 1970-1973

\section{Entrevistas}

Jaime Baier, 17 de noviembre de 2009

Victor Carmine, Temuco, 19 de noviembre de 2009

Julio Contreras, Temuco, 13 de mayo de 2010

Irma Felber, Temuco, 13 de mayo de 2010

Jorge Lavandero, Santiago, 10 de junio de 2010

Victor Maturana, Temuco, 21 de octubre de 2009

Mario Rivas, Temuco, 9 de noviembre de 2009

Eduardo Sabugo, Temuco, 24 de noviembre de 2009

Gastón Sepúlveda, Temuco, 9 de octubre de 2009

Rodrigo Undurraga, Quepe, 22 de diciembre de 2009

Artículo traducido por Soledad Novoa Donoso 